\title{
¿En qué se equivoca el realismo jurídico?*
}

\author{
What Is Wrong with Legal Realism?
}

Giovanni Tuzet**

Recepción y evaluación de propuesta: 24/10/2017

Aceptación: 26/02/2018

Recepción y aceptación final: 16/08/2018

Resumen: El libro Legalidad de Scott Shapiro se propone llevar a cabo una estimulante, pero ardua, tarea filosófica, a saber: ofrecer una explicación de aquello que el derecho es y de por qué vale la pena tenerlo. $\mathrm{Su}$ "Teoría del derecho como plan" aborda la primera cuestión en términos de la denominada tesis de los "hechos sociales" y la segunda en términos de la tesis del "fin moral". Así, el derecho está determinado únicamente por hechos sociales, pero posee un punto moral, puesto que la finalidad de la actividad legal es solucionar algunos problemas morales. Las escuelas filosófico-jurídicas del siglo veinte se han dividido acerca de estos temas. Entre tales escuelas, Shapiro rechaza la visión realista porque deja de lado el punto de vista interno. Sin embargo, muchas afirmaciones realistas se referían al conocimiento del derecho, no a su normatividad. El artículo aborda este punto recordando también el debate entre Hart y Ross.

Palabras clave: conocimiento del derecho, Hart, hombre malo, realismo jurídico, Ross, Shapiro.

Abstract: Shapiro's book Legalidad engages in a difficult and exiting philosophical task: giving an account of what law is and of why it is worth having. His "Planning Theory of Law" addresses the first issue in terms of the so-called "Social Facts" thesis and the second in terms

* Traducción del inglés por Federico José Arena.

** Profesor de Filosofía del derecho, Università Bocconi, Milán, Italia.

E-mail: giovanni.tuzet@unibocconi.it 
of the "Moral Aim" thesis: law is determined by social facts alone, but it has a moral point, for the aim of legal activity is to remedy some moral deficiencies. Twentieth century jurisprudential schools divided on such topics. Among such schools, Shapiro rejects the realist view because it leaves out of the picture the internal point of view. However, many realist claims were about legal knowledge, not about legal normativity. The paper addresses this point recalling also the debate between Hart and Ross.

Keywords: bad man, Hart, legal knowledge, legal realism, Ross, Shapiro.

\section{Otra vez el realismo}

El libro Legalidad de Scott Shapiro se propone llevar a cabo una estimulante, pero ardua, tarea filosófica, a saber, ofrecer una explicación de aquello que el derecho es y de por qué vale la pena tenerlo. Su "Teoría del derecho como plan" aborda la primera cuestión en términos de la denominada tesis de los "hechos sociales" y la segunda en términos de la tesis del "fin moral". Así, el derecho está determinado únicamente por hechos sociales, pero posee un punto moral, puesto que la finalidad de la actividad legal es solucionar algunos problemas morales. Las escuelas filosófico-jurídicas del siglo veinte se han dividido acerca de estos temas. El iusnaturalismo se preocupó principalmente por los valores del derecho y su dimensión moral, mientras que el positivismo jurídico y el realismo jurídico se interesaron sobre todo por sus propiedades fácticas. Shapiro intenta ofrecer un cuadro unificado de estas cuestiones, aun cuando el campo de la filosofía del derecho sigue (y probablemente seguirá) siendo un campo de batalla, donde numerosos ejércitos filosóficos se contienden ciertas áreas del territorio.

Aquí me referiré al realismo jurídico en particular. Escritos recientes de filosofia política y jurídica han procurado recuperar los métodos y las ideas del realismo jurídico del siglo veinte ${ }^{1}$. Luego de que Richard Posner

1 Ejemplos significativos de esta corriente son Leiter, B., Naturalizing Jurisprudence. Essays on American Legal Realism and Naturalism in Legal Philosophy, Oxford, Oxford University Press, 2007; Posner, R. A., How Judges Think, Cambridge and London, Harvard University Press, 2008; Miles, T. J. y Sunstein, C. R., "The New Legal Realism”, University of Chicago Law Review, 75, 2008, pp. 831-851; Nourse, V. y Shaffer, 
¿En qué se equivoca el realismo jurídico?

diera nueva vida al realismo dentro del esquema del análisis económico del derecho ${ }^{2}$ y luego de que la lectura posmoderna que los integrantes de movimiento Critical Legal Studies hicieron de los realistas durante los ochenta y los noventa ${ }^{3}$, actualmente Brian Leiter, en particular, ha llamado otra vez nuestra atención hacia la metodología y las tesis realistas ${ }^{4}$.

Shapiro no sigue esta línea. Mientras que Leiter, inspirándose en los realistas, asume el proyecto de naturalizar la filosofía del derecho, Shapiro se apega al método del análisis conceptual. Shapiro ni siquiera menciona al realismo jurídico en la primera parte de su libro, en la que se ocupa de la filosofía del derecho, del concepto de derecho, de hechos jurídicos, de la teoría de la sanción de Austin y de la regla de reconocimiento de Hart ${ }^{5}$. Sin embargo, el realismo desempeñó un papel muy relevante en las discusiones que, durante el siglo veinte, se llevaron adelante sobre esos temas. ¿Por qué Shapiro no lo menciona? ¿E1 realismo jurídico estaba completamente equivocado? Y si es así, ¿en qué se equivocaba? Creo que la respuesta, sobre la cual estaría de acuerdo Shapiro, es la siguiente: el realismo deja fuera del cuadro el punto de vista interno. Esta es la razón principal por la que el realismo ha sido considerado una teoría del derecho con fisuras. Claramente, el realismo jurídico se ocupa del derecho solo desde el punto de vista externo, sin tomar en consideración las razones sobre la base de las

G., "Varieties of New Legal Realism: Can a New World Order Prompt a New Legal Theory?", Cornell Law Review, 95, 2009, pp. 61-137.

2 Véase Posner, R. A., The Economics of Justice, Cambridge and London, Harvard University Press, 1981 y Id., The Problems of Jurisprudence, Cambridge and London, Harvard University Press, 1990. Véase también Chiassoni, P., "Richard Posner: pragmatismo e analisi economica del diritto", en Zanetti, G. (ed.), Filosofi del diritto contemporanei, Milano, Raffaello Cortina, 1999, pp. 183-220.

3 Véase, e. g., Minda, G., Postmodern Legal Movements. Law and Jurisprudence at Century's End, New York, New York University Press, 1995.

4 Véase Leiter, B., op. cit. Sobre el enfoque de Leiter, véase por ejemplo Priel, D., "Were the Legal Realists Legal Positivists?", Law and Philosophy, 27, 2008, pp. 309-350; Spaak, T., Reseña de "Naturalizing Jurisprudence" de B. Leiter, Theoria, 74, 2008, pp. 352-362; Green, L., "Law and the Causes of Judicial Decisions", University of Oxford Legal Research Paper Series, 14/2009, pp. 1-36.

5 El realismo es analizado en el capítulo 9 del libro de Shapiro, en relación con la crítica que el realismo hiciera del formalismo en las decisiones judiciales. 
cuales los ciudadanos y los funcionarios asumen el derecho como guía, aceptan sus normas, las siguen, critican a quienes no se conforman a ellas, etc. Podría incluso agregarse que dejar fuera el punto de vista interno es consecuencia del hecho de que el realismo está comprometido con la empresa de reducir las normas a hechos, suprimiendo así la normatividad. La normatividad del derecho y el punto de vista interno pierden todo interés una vez que se advierte que no son más que epifenómenos de hechos sociales y psicológicos; sin embargo, suele argumentarse contra el realismo, este no parecería ser un buen análisis de nuestro concepto de derecho. Hart construyó una crítica de este tipo contra el realismo y, si estoy en lo correcto, Shapiro concuerda completamente con él ${ }^{6}$.

Creo que la crítica de Hart es básicamente correcta. Pienso también que uno de los objetivos que Shapiro pretende alcanzar en su libro es precisamente el de dar una explicación de aquello que los realistas aparentemente perdían de vista. Se trata de explicar por qué usamos al derecho como guía, por qué nos preocupamos y deberíamos preocuparnos por el derecho, por qué es tan importante para nuestras vidas como individuos y como grupo social. Sin embargo, creo que la reconstrucción hartiana del realismo era una simplificación, poco caritativa y equivocada en algunos aspectos, puesto que desatendía algunos aspectos del proyecto realista. Si esto es correcto, vale la pena dar una mirada más atenta a estas cuestiones, no solo por razones históricas, sino también teóricas, de modo tal de comprender mejor el proyecto mismo de Shapiro y determinar el alcance de su tesis.

6 Véase Hart, H. L. A. (1961), The Concept of Law, Second Edition, Oxford, Oxford University Press, 1994, caps. 1 y 7. [N. T.: citado por la traducción de la primera edición de Genaro Carrió: Hart, H. L. A., El concepto de derecho, Buenos Aires, Abeledo-Perrot, 1963. En paréntesis se indican las páginas correspondientes a la traducción]. "Es bastante conocido el modo en que Hart ridiculizaba la teoría de las normas defendida por el realismo jurídico. Según Hart es absurdo sostener que las normas jurídicas son meramente predicciones del comportamiento de los jueces, puesto que entonces ¿cómo podría un juez decidir un caso? ¿debería usar las normas para predecir su propio comportamiento? Las normas jurídicas permiten a las personas predecir el comportamiento judicial porque guían el comportamiento de los jueces, y no viceversa" (Shapiro, S., "On Hart's Way Out", Legal Theory, 4, 1998, pp. 469-507, cita en la p. 503). 
¿En qué se equivoca el realismo jurídico?

\section{Teorías basadas en la sanción y el hombre malo}

De hecho, en la primera parte del libro de Shapiro no hay ninguna mención explícita al realismo, sino que se hace referencia a él solo de manera implícita. Mientras discute sobre la tarea del filósofo del derecho, consistente en formular una lista preliminar de verdades obvias acerca del derecho, Shapiro se refiere al punto de vista que por lo general se atribuye al realismo y según el cual el derecho es lo que los tribunales dicen que es.

Supongamos $[\ldots]$ que alguien propone la siguiente explicación de la naturaleza del derecho: el derecho es lo que los tribunales dicen que es. Aunque esta teoría está muy difundida entre los políticos y los profesores de derecho, es claro que no logra ser una instancia de análisis conceptual, en tanto deja de lado muchas verdades obvias sobre el derecho ${ }^{7}$.

El método de análisis conceptual que usa Shapiro parte de un conjunto de verdades obvias acerca del derecho, y una teoría que no logra acomodar varias de ellas ha de ser rechazada, tal como sucede con el realismo. ¿Cuáles son las verdades obvias que el realismo no logra acomodar? Principalmente, la verdad obvia referida a la objetividad, "que sostiene que los tribunales pueden cometer errores al interpretar el derecho"8. Shapiro menciona otras verdades obvias que el realista no logra acomodar, pero me parece que se trata de variantes sobre el tema de la objetividad:

que algunos tribunales aplican un mejor razonamiento jurídico que otros, que los tribunales de apelación existen en parte para corregir los errores jurídicos y que la razón por la cual normalmente podemos predecir lo que determinarán los tribunales es que estos suelen aplicar correctamente el derecho preexistente ${ }^{9}$.

7 Shapiro, S., Legalidad, Madrid-Barcelona, Marcial Pons, 2014, p. 42.

8 Ídem. Véase Leiter, B., op. cit., p. 70.

9 Shapiro, S., Legalidad, op. cit., p. 42. 
Mi impresión es que tenemos razones para dudar que el realismo "deja de lado tantas verdades obvias que no puede considerarse que revele la identidad de la entidad referida por nuestro concepto de derecho" ${ }^{10}$. E incluso más, Shapiro deja espacio para la posibilidad de que una respuesta acerca de la identidad de un ente determinado viole una o más de las verdades obvias.

\begin{abstract}
Aunque no es necesario que nuestra respuesta satisfaga cada una de las verdades obvias, debemos intentar elaborar una teoría que dé cuenta de tantas como sea posible. Porque si nuestra explicación deja de lado demasiadas de ellas, habremos cambiado de tema y ya no estaremos brindando una explicación de la entidad que pretendíamos, sino de algo distinto ${ }^{11}$.
\end{abstract}

Dado que un conjunto de enunciados que contiene un enunciado falso es también falso, creo que una teoría que viole una o más obviedades acerca de la entidad en cuestión es falsa. Pero Shapiro parece sostener que, bajo ciertas condiciones (i.e. ¿ausencia de una teoría mejor?), una teoría que viole algunas verdades obvias puede de todos modos ser aceptada. Esto me parece un tanto desconcertante, sin embargo, aun cuando compartamos esta afirmación acerca de los criterios de aceptación de una teoría, uno desearía saber algo más acerca del número y el tipo de obviedades que una teoría puede legítimamente violar.

Más allá de estas cuestiones preliminares, quisiera concentrarme en el tratamiento, si bien implícito, que Shapiro da al enfoque realista y, en particular, en su discusión, ahora sí explícita, de la perspectiva del hombre malo (bad man). Como dije al inicio, el principal defecto del enfoque realista consiste en su ceguera frente al punto de vista interno. Quizás, la obviedad acerca del derecho que no ven los realistas es la siguiente: las normas jurídicas, tal como afirma Hart, poseen un aspecto interno. Ahora bien, la perspectiva del hombre malo parece

${ }^{10}$ Ídem. Sin embargo, siguiendo a Hart, podríamos decir que el realismo no puede dar cuenta de las reglas secundarias, ya sea de la "regla de reconocimiento" o de las "reglas de adjudicación". Véase Hart, H. L. A., op. cit., caps. 5-7. 
¿En qué se equivoca el realismo jurídico?

desafiar esta crítica al realismo, puesto que a partir de ella parece posible construir un ataque radical a la normatividad del derecho y a la idea de que el punto de vista interno es esencial para definir el derecho.

La perspectiva del hombre malo es introducida por Shapiro en el capítulo dedicado a la teoría de Austin basada en la sanción, y luego discutida en el capítulo acerca de la regla de reconocimiento de Hart ${ }^{12}$. Shapiro básicamente reproduce la crítica de Hart a Austin, y considera que la crítica es correcta. Lo que me parece desconcertante es el modo en el que se presenta y se discute la perspectiva del hombre malo.

Pienso que -tal como intentaré mostrar en lo que sigue- el punto de Holmes era distinto del que Shapiro y otros le atribuyen. El punto de Holmes era acerca del conocimiento jurídico, y no acerca de la normatividad del derecho. Más precisamente, el personaje del hombre malo no nos ayuda a establecer si debemos o no hacer lo que el derecho nos exige, si el derecho es o no una razón para actuar, etc.; nos ayuda, en cambio, a obtener conocimiento acerca del derecho.

Si consideramos al personaje del hombre malo como un modo de dar cuenta de la normatividad del derecho (o del derecho como razón para actuar y como guía de comportamiento), por supuesto que es un modo insatisfactorio. Al igual que la teoría basada en la sanción de Austin, la teoría del hombre malo "no deja lugar a la existencia del buen ciudadano" ya que se concentra solo en quien se ve motivado únicamente por el deseo de evitar las sanciones ${ }^{13}$.

Por otra parte, el buen ciudadano considera que las obligaciones impuestas por el derecho brindan una nueva razón moral para el cumplimiento. Se entiende que las reglas son razones más allá de las sanciones que acompañarán su violación o de las

12 Shapiro, S., Legalidad, op. cit., caps. 3-4. Véase Shapiro, S. J., "The Bad Man and the Internal Point of View", en Burton, S. J. (ed.), The Path of the Law and its Influence, Cambridge, Cambridge University Press, 2000, pp. 197-210 y Id., "Law, Plans, and Practical Reason", Legal Theory, 8, 2002, pp. 387-441, en particular pp. 437-439.

${ }^{13}$ Shapiro, S., Legalidad, op. cit., p. 104. Véase también Shapiro, S., "What is the Internal Point of View?", Fordham Law Review, 75, 2006, pp. 1157-1170, en particular p. 1159; en contra, véase Schauer, F., "Was Austin Right After All? On the Role of Sanctions in a Theory of Law", Ratio Juris, 23, 2010, pp. 1-21. 
consideraciones morales que, con independencia de lo anterior, resulten aplicables a las acciones exigidas ${ }^{14}$.

Para el hombre malo, el único aporte normativo que hace el derecho es la amenaza de sanción. Mientras que el derecho ciertamente busca controlar al hombre malo, y por esta razón amenaza en general con sanciones, también desea guiar la conducta del buen ciudadano. No solo las sanciones son innecesarias para controlar a quienes respetan las reglas del sistema que confieren potestades e imputan legitimidad a quienes actúan en conformidad con ellas, sino que son terriblemente costosas. Motivar a los buenos ciudadanos imponiéndoles deberes jurídicos es mucho más eficiente que amenazarlos verosímilmente. En efecto, un régimen cuyo único medio de persuasión fuese la fuerza quebraría al poco tiempo ${ }^{15}$.

Siguiendo a Shapiro, esto permite una comprensión complementaria del hombre malo de Holmes (que desea evitar las sanciones) y del asaltante de Austin (que amenaza con sanciones) y es una mala noticia para la teoría hartiana de las reglas como prácticas, puesto que el hombre malo es capaz de formular proposiciones jurídicas, sin asumir el punto de vista interno respecto de la regla de reconocimiento del sistema.

Considérese el hombre malo. Para él, el derecho brinda la misma razón básica que genera el asaltante, a saber, la evitación de las sanciones. Obedece el derecho por autointerés racional, porque "se ve obligado" a hacerlo. Sin embargo, adviértase que el hombre malo es capaz de recaracterizar el derecho utilizando un vocabulario alternativo. Mientras que el hombre malo puede describir el derecho en los mismos términos que usaría respecto de un asalto -"me vi obligado a entregar el dinero"- también puede redescribir lo anterior empleando el lenguaje de la obligación. Podría decir no solo que el derecho le obliga a pagar 
¿En qué se equivoca el realismo jurídico?

impuestos, sino también que está jurídicamente obligado a hacerlo. Es decir, puede describir las normas impositivas no solo como expresión de deseos respaldados por amenazas de sanción sino también como reglas que imponen deberes jurídicos ${ }^{16}$.

No sé si se trata realmente de malas noticias para $\operatorname{Hart}^{17}$, pero sospecho que seguramente son buenas noticias para el realismo jurídico, entendido no como una teoría del derecho sino como una teoría acerca del conocimiento jurídico. El hombre malo puede redescribir el derecho usando un vocabulario y una terminología normativos, aun cuando asuma un punto de vista externo. Éste es exactamente el punto. El hombre bueno corre el peligro de confundir las obligaciones morales con las jurídicas, mientras que, cuando nosotros deseamos conocer el derecho, queremos saber qué es específicamente jurídico. El hombre malo nos ayuda a hacer esto ${ }^{18}$. En la sección siguiente intentaré explicar con más detalle cómo es que esto es así.

Por esta razón, desde mi punto de vista, es equivocada la acusación según la cual en este caso se produce una violación de la ley de Hume puesto que se llevaría a cabo un razonamiento del tipo DENS (derivando lo normativo a partir de lo descriptivo $)^{19}$. Si consideramos la perspectiva del hombre malo en sus propios términos (algo que no interesaba a Holmes), se trata de una perspectiva práctica consistente en un razonamiento del tipo NENS (en el que la normatividad es claramente prudencial, no legal). Se trata de derivar una conclusión normativa a partir de una premisa normativa y una descriptiva. Por ejemplo ("i!" designa la fuerza normativa de un enunciado, "/" separa las premisas entre sí y "//" separa las premisas de la conclusión):

16 Shapiro, S., Legalidad, op. cit., p. 151-152.

${ }^{17}$ Sobre esta cuestión véanse las contribuciones Poggi y Papayannis presentes en este volumen.

${ }^{18}$ Véase Shapiro, S., Legalidad, op. cit., p. 239-241, acerca de las supuestas ventajas de la teoría de los planes respecto de la explicación del modo en que el hombre malo puede descubrir el contenido del derecho, sin asumir el punto de vista interno.

19 Shapiro, S., Legalidad, op. cit., p. 153. 
(1)

¡Deseo evitar las sanciones! /

Si no hago A, (probablemente) seré sancionado por un tribunal // ¡Debo hacer $\mathrm{A} !^{20}$

Ahora bien, si consideramos la perspectiva del hombre malo como una perspectiva epistémica (que interesaba a Holmes), no se trata de un razonamiento del tipo DENS, sino del tipo DEDS, en el que se obtiene una conclusión descriptiva a partir de premisas igualmente descriptivas:

(2)

Si A es un deber jurídico, (probablemente) será impuesto por los tribunales /

$\mathrm{X}$ no ha hecho A //

$\mathrm{X}$ será (probablemente) sancionado por un tribunal.

$\mathrm{Ni}$ (1) ni (2) equivalen a una teoría del derecho, pero (2) contribuye al conocimiento jurídico formulando predicciones acerca de lo que harán los funcionarios, y por lo tanto podría ser parte de una teoría del derecho, que podríamos llamar "teoría predictiva", acerca del modo en el que nuestros enunciados externos sobre el derecho pueden verse, en un sentido relevante, empíricamente confirmados o no.

Quizás si -sobre esta base- se analiza nuevamente la afirmación original de Holmes referida a la perspectiva del hombre malo, pueda arrojarse luz sobre estos temas, o al menos así lo espero.

${ }^{20}$ Esto puede también ser visto como un razonamiento del tipo DEDS si lo redescribimos en términos de enunciados acerca de "normas técnicas" (von Wright, G. H., Norm and Action, London, Routledge \& Kegan Paul, 1963, caps. 1 y 6), susceptibles de ser verdaderos o falsos: "Deseo evitar ser sancionado / Si deseo evitar ser sancionado, tengo que hacer A // Tengo que hacer A". 
¿En qué se equivoca el realismo jurídico?

\section{III. ¿En qué se equivoca el hombre malo?}

Austin se concentra en las sanciones, que son el elemento central de su teoría "imperativista" del derecho. Según esta teoría las normas jurídicas son órdenes del soberano, es decir, deseos del soberano respaldados por amenazas. Holmes y Ross se concentran, en cambio, en la predicción. Me referiré a la posición de Ross en la sección siguiente. En esta sección desearía concentrarme en las razones que llevan a Holmes a concentrarse en la predicción.

El hombre malo de Holmes aparece por primera vez en el discurso que Oliver Wendell Holmes pronunció cuando fue inaugurado el nuevo salón de la Boston University School of Law, el 8 de enero de 1897. El discurso fue luego publicado en la Harvard Law Review bajo el título "The Path of the Law". No carece de importancia advertir que los destinatarios del discurso original eran, presumiblemente, estudiantes y profesores de derecho.

El tema abordado por Holmes es "el estudio del derecho". Para saber qué establece el derecho, es necesario formular predicciones acerca de las acciones de los funcionarios y, en particular, acerca de las decisiones judiciales.

Lo que llamamos un deber jurídico no es otra cosa más que una predicción según la cual si un hombre hace o deja de hacer una cierta cosa será sometido a un cierto sufrimiento en virtud de una sentencia judicial -y lo mismo para el caso de los derechos legales $^{21}$.

El patrón de razonamiento (2) que he presentado más arriba no es más que una aplicación de esto. ¿Por qué llevamos a cabo predic-

${ }^{21}$ Holmes, O. W., "The Path of the Law", Harvard Law Review, 10, 1897, pp. 457-478, cita en la p. 458. Sobre "The Path of the Law" véase Fisch, M. H., "Justice Holmes, the Prediction Theory of Law, and Pragmatism", The Journal of Philosophy, 39, 1942, pp. 85-97; Twining, W., "The Bad Man Revisited”, Cornell Law Review, 58, 1973, pp. 275-303; Miller, J. D., "Holmes, Peirce and Legal Pragmatism", The Yale Law Journal, 84, 1975, pp. 1123-1140; Grey, T. C., "Holmes and Legal Pragmatism", Stanford Law Review, 41, 1989, pp. 787-870; Burton, S. J., op. cit. 
ciones acerca de las decisiones judiciales? Para distinguir el derecho de la moral y para distinguir el derecho concreto (lo que establece el derecho) del derecho en abstracto (lo que el derecho es). Es en este punto que entra en acción el hombre malo. El hombre malo, según la definición de Holmes, no se preocupa por la moral, las normas éticas o los principios compartidos por sus pares, sino que se comporta de acuerdo a su propio interés. En particular, desea evitar ser sancionado por los tribunales. De este modo, el hombre malo lleva a cabo el tipo de razonamiento (1) que he presentado arriba y esto es de gran importancia puesto que, desde el punto de vista de Holmes, nos da un método para evitar confundir el derecho con la moral:

Creo que conviene aquí [...] señalar y aclarar una confusión entre derecho y moral que a veces suele elevarse hasta alcanzar el estatuto de teoría [...]. Es bastante obvio que un hombre malo tiene tantas razones como el bueno para desear evitar enfrentarse a la fuerza pública, y así puede advertirse la importancia práctica de la distinción entre derecho y moral. Un hombre que no dé ninguna importancia a las reglas éticas defendidas y practicadas por sus vecinos, se preocupará de todos modos por evitar que lo fuercen a entregar dinero y, seguramente, intentará también evitar terminar tras las rejas ${ }^{22}$.

El razonamiento del hombre malo es práctico, pero el razonamiento del estudioso del derecho que adopta la perspectiva del hombre malo, para distinguir el derecho de la moral, no lo es. Holmes subraya el carácter epistémico de la perspectiva de su personaje, que es perfectamente compatible con reconocer el hecho de que el derecho "es el testigo y el depositario externo de nuestra vida moral".

${ }^{22}$ Holmes, O. W., op. cit., p. 459. Shapiro, S. J., "What is the Internal Point of View?", op. cit., p. 1161 caracteriza al punto de vista del hombre malo como un punto de vista externo y práctico, constituido por una actitud de no-aceptación. (Pero "externo y práctico" suena a un oxímoron, en el caso que externo signifique no práctico, i. e. teórico). Perry, S. R., "Holmes versus Hart: The Bad Man in Legal Theory", en Burton, S. J., op. cit., pp. 158-196, lo caracteriza como "hermenéutico", en el sentido de "embarcado en un ejercicio de razonamiento práctico". 
¿En qué se equivoca el realismo jurídico?

Estoy seguro que ninguno de mis oyentes cometerá el error de interpretar lo que tengo para decir como una expresión de cinismo. El derecho es el testigo y el depositario externo de nuestra vida moral. Su historia es la historia del desarrollo moral de la raza. La práctica del derecho, a pesar de lo que afirma el humor popular, tiende a producir buenos ciudadanos y buenos hombres. Cuando resalto la diferencia entre el derecho y la moral, lo hago teniendo en vista un único fin, a saber, el de aprender y comprender el derecho ${ }^{23}$.

Si queremos conocer el derecho tal y como es, y no como debería ser según un determinado estándar moral, debemos mirar el derecho tal y como lo hace el hombre malo, ya que su razonamiento no confunde el derecho con la moral. No es necesario dar por buenas sus razones prudenciales, apoyadas en predicciones, es necesario únicamente usar su razonamiento como una guía epistémica para llevar a cabo predicciones acertadas ${ }^{24}$. Por el contrario, el razonamiento del hombre bueno que desea comportarse sobre la base de razones morales (que pueden ciertamente ser diferentes de las razones legales) no confiere una guía epistémica. El pasaje clave es el siguiente:

Si usted desea conocer lo que exige el derecho y no otra cosa, debe mirar el derecho como un hombre malo, como un hombre que se preocupa sólo por las consecuencias materiales que ese conocimiento le permite predecir; no debe mirar el derecho como un hombre bueno, como un hombre que encuentra las

${ }^{23}$ Holmes, O. W., op. cit., p. 459; el énfasis es mío.

${ }^{24}$ Shapiro está en lo cierto cuando observa que "el hombre malo de Holmes no se ve motivacionalmente guiado por el derecho; sin embargo, el derecho guía epistemológicamente su conducta, al menos en aquellos casos en que las normas jurídicas se encuentran correlacionadas con la imposición, o el riesgo de imposición, de sanciones significativas" (Shapiro, S. J., "Law, Morality, and the Guidance of Conduct", Legal Theory, 6, 2000, pp. 127-170, cita en las pp. 146-147). Acerca de la guía epistémica y la guía motivacional, véase Shapiro, S. J., "On Hart's Way Out", op. cit., p. 490 y ss. También Leiter, B., op. cit., pp. 104-106 afirma que la tesis de Holmes era epistémica, y subraya que "Hart leyó mal a los realistas cuando los interpretó como respondiendo a cuestiones filosóficas de análisis conceptual" (ibidem, p. 18). 
razones de sus acciones, ya sea dentro o fuera del derecho, en las sanciones indefinidas de la consciencia ${ }^{25}$.

Holmes da varios ejemplos de esto. Un ejemplo significativo se refiere a los denominados "derechos del hombre". Incluso si la moral ha desde siempre influenciado el derecho, Holmes sostiene que "se obtiene únicamente confusión si se asume que los derechos del hombre en sentido moral son igualmente derechos en el sentido de la Constitución o las leyes" 26.

En definitiva, en primer lugar, la perspectiva del hombre malo nos ayuda a distinguir el derecho de la moral. En segundo lugar, gracias a las predicciones, nos ayuda a distinguir el derecho existente (el derecho vigente) del derecho en abstracto. Holmes concluye su argumento con la famosa frase sobre "las profecías de lo que, de hecho, harán los tribunales":

La confusión de la que me estoy ocupando afecta todas las concepciones legales. Considere la pregunta fundamental: ¿qué constituye el derecho? Encontrará algunos escritores que le dirán que el derecho es algo distinto de las decisiones de los tribunales de Massachusetts o Inglaterra, que es un sistema de la razón, que se deduce de los principios de la moral o de determinados axiomas o de lo que sea, y que puede o no coincidir con las decisiones. Pero si tomamos en cuenta el punto de vista de nuestro amigo el hombre malo, advertiremos que él no se preocupa en lo más mínimo por los axiomas o las deducciones. El hombre malo quiere saber lo que, de hecho, harán los tribunales del Massachusetts o de Inglaterra. Yo estoy bastante de acuerdo con él. Las profecías de lo que, de hecho, harán los tribunales, y solo eso, es lo que entiendo por derecho ${ }^{27}$.

${ }^{25}$ Holmes, O. W., op. cit., p. 459.

${ }^{26}$ Ibidem, p. 460.

${ }^{27}$ Ibidem, pp. 460-461; las cursivas son mías. 
¿En qué se equivoca el realismo jurídico?

Hay, a pesar de todo, algunos pasajes desafortunados en el argumento de Holmes. El pasaje apenas citado puede dar la impresión de que lo que está en cuestión es la naturaleza del derecho ("¿qué constituye el derecho?"). Otros pasajes de ese mismo escrito pueden dar la misma impresión:

Los derechos y los deberes primarios de los que se ocupa la ciencia del derecho no son, de nuevo, otra cosa más que profecías ${ }^{28}$.

El deber de cumplir un contrato, significa en el derecho una predicción de que usted deberá resarcir los daños en el caso que no lo cumpla, y sólo eso ${ }^{29}$.

Estos pasajes dan la impresión de que Holmes está ofreciendo una reconstrucción conceptual del derecho. Esta impresión se ve reforzada si se leen los pasajes en los que Holmes critica las teorías de acuerdo con las cuales un derecho o un deber jurídico son "algo que existe separada e independientemente de las consecuencias de su quebrantamiento, y al que determinadas sanciones son sucesivamente asociadas"30. Aquí Holmes ofrece una teoría del derecho basada en la sanción. Y en cuanto tal se ve expuesto a las bien fundadas objeciones que Hart y Shapiro formulan contra este tipo de teorías.

Algunos autores han intentado defender el enfoque de Holmes frente a estas objeciones, afirmando, por ejemplo, que Holmes no buscaba proveer una teoría semántica del significado de "derecho", sino una teoría empírica de la conexión entre deberes jurídicos y decisiones judiciales ${ }^{31}$. Otros sostienen que la perspectiva del hombre malo es solo

28 Ibidem, p. 458.

${ }^{29}$ Ibidem, p. 462. Véase la crítica a este pasaje y a otros similares en Kelsen, H., General Theory of Law and State (1945), New York, Russell \& Russell, 1961, pp. 166-169.

${ }^{30}$ Holmes, O.W., op. cit., p. 458.

31 Véase White, M., "Holmes and Hart on Prediction and Legal Obligation", Transactions of the Charles S. Peirce Society, 2004, 40, pp. 569-573. 
un "dispositivo heurístico" adoptado para distinguir el derecho de la moral, y el derecho actual del derecho en abstracto ${ }^{32}$.

De todos modos, además de las cuestiones y los escrúpulos filológicos, es razonable decir que "The Path of the Law" admite dos lecturas diferentes, una conceptual y otra empírica. Según la primera, el derecho no es otra cosa más que profecías, según la segunda, el conocimiento del derecho exige llevar a cabo predicciones de las decisiones judiciales.

Un punto epistémico importante debe ser aclarado antes de continuar: he dicho que las teorías predictivas han de ser interpretadas como teorías del conocimiento jurídico, pero no debería confundirse predicción con conocimiento. Una predicción tiene un contenido proposicional capaz de ser verdadero o falso, y en el caso que sea falso no es conocimiento, claramente. Pero las predicciones son, de todos modos, "dispositivos heurísticos" quizás indispensables para obtener un conocimiento completo del derecho vigente. Las predicciones han de ser testeadas para ver si la hipótesis sobre la que se basan es verdadera o falsa.

Hart y Shapiro demuestran que, si la lectura conceptual de los escritos de Holmes es correcta, entonces la teoría de Holmes es equivocada. Pero ello no implica que la teoría de Holmes sea también errónea si se le da una lectura epistémica. De hecho, Ross defendió una posición similar de un modo que, desde mi punto de vista, es bastante persuasivo. Veamos con más detalle la posición realista de Ross.

\section{Acerca de la teoría predictiva como teoría del conocimiento jurídico}

\section{IV.1. La crítica de Hart}

En "Scandinavian realism", que es una reseña del libro de Alf Ross On Law and Justice publicado un año antes, Herbert Hart presentó una The American Journal of Jurisprudence, 50, 2005, p. 71-105, en particular pp. 86-87. 
¿En qué se equivoca el realismo jurídico?

severa crítica al pensamiento de $\operatorname{Ross}^{33}$. Según esta crítica, las teorías predictivas se equivocan desde un punto de vista conceptual y son inadecuadas desde un punto de vista explicativo. Primero, es un error conceptual reducir la validez legal a predicciones empíricas. Segundo, al traducir los enunciados internos a enunciados externos se pierde tanto el sentido que poseen el lenguaje y la práctica jurídicos como la diferencia entre "verse obligado" y "tener una obligación" 34.

La reconstrucción que Hart hace de Ross se concentra en el aspecto predictivo de la teoría rossiana y en el hecho que esta toma en cuenta las actitudes emocionales de los tribunales: ambas cosas son necesarias, según Ross, para determinar cuándo una norma jurídica es "válida" ("válida" dentro del esquema de Ross).

Decir que una norma jurídica es válida es decir (1) que los tribunales, bajo ciertas condiciones específicas, aplicarán esa norma, o al menos que la considerarán especialmente importante para tomar su decisión y (2) lo harán porque se sienten emocionalmente "obligados" por esas normas. Una norma válida es una hipótesis verificable acerca del comportamiento futuro de los jueces y de los específicos sentimientos que lo motivan $^{35}$.

El segundo punto es importante para distinguir el realismo de Ross de aquella forma cruda de realismo para la cual solo cuenta el comportamiento de los jueces. El comportamiento no basta para ofrecer una explicación del derecho válido y de la aplicación del derecho, para ello ha de tenerse en cuenta también las actitudes de los jueces y la convicción de "sentirse obligado" por las normas. Sin embargo, Hart piensa que el enfoque de Ross no es capaz de dar cuenta del modo en que los jueces toman sus decisiones:

${ }^{33}$ Hart, H. L. A., "Scandinavian Realism" (1959), en Id., Essays in Jurisprudence and Philosophy, Oxford, Clarendon Press, 1983, pp. 161-169. Véase Ross, A., On Law and Justice, London, Stevens \& Sons, 1958. Véase Shapiro, S. J., "What is the Internal Point of View?", op. cit., pp. 1168-1170.

34 Véase Hart, H. L. A., The Concept of Law, op. cit., cap. 2 y Kelsen, H., op. cit., p. 165 y ss.

35 Hart, H. L. A., "Scandinavian Realism", op. cit., p. 165. 
Primero, incluso si en boca del ciudadano ordinario "Esto es derecho Inglés válido" es una predicción de lo que un juez hará, dirá o siente, éste no puede ser el significado en la boca de un juez, quién no está preocupado por predecir sus propios sentimientos o comportamiento, ni los de sus colegas. "Esta es una norma de derecho válida" dicho por un juez es un acto de reconocimiento; al pronunciarlo el juez reconoce la norma en cuestión como una que satisface un criterio aceptado y general para la admisión de una norma como parte del sistema y, por lo tanto, como un estándar jurídico de comportamiento ${ }^{36}$.

Segundo, incluso si (aun cuando también pueda dudarse de esto) los enunciados no-judiciales de la forma " $\mathrm{X}$ es una norma válida" sean siempre predicciones de los sentimientos y del comportamiento futuros de los jueces, la base para tales predicciones es el conocimiento de que los jueces usan y comprenden el enunciado "Esta es una norma válida" en un sentido no-predictivo ${ }^{37}$.

Hart señala en este punto la diferencia entre enunciados internos y enunciados externos. Los últimos son enunciados factuales "acerca del grupo y de la eficacia de sus reglas" 38 . Los primeros son enunciados normativos que "expresan la aceptación de los estándares y, de manera diversa, los usan y apelan a ellos" 39 . Ross, según Hart, trata los enunciados de validez como enunciados externos que pretenden predecir el comportamiento y los sentimientos de los jueces, sin embargo, siempre según Hart, "el uso central de 'legalmente válido' es en un enunciado normativo interno" 40 .

${ }^{36}$ Ídem. Como puede advertirse, Hart está pensando aquí en lo que denomina "regla de reconocimento". Véase Shapiro, S., "On Hart's Way Out”, op. cit., y Shapiro, S., Legalidad, op. cit., cap. 4.

${ }^{37}$ Hart, H. L. A., "Scandinavian Realism", op. cit., p. 165.

38 Ibidem, p. 166.

39 Ibidem, p. 167. Véase Muffato, N., "Asserti interni: prescrizioni o asserzioni?", en Comanducci, P. y Guastini, R. (eds.), Analisi e diritto 2007, Torino, Giappichelli, 2007, pp. 11-37.

${ }^{40}$ Hart, H. L. A., “Scandinavian Realism”, op. cit., p. 167. Véase Ross, A., op. cit., cap. 2. 
¿En qué se equivoca el realismo jurídico?

Del mismo modo, refiriéndose a los que Hart llama "enunciados de obligación", "la objeción fundamental es que la interpretación predictiva oscurece el hecho de que, cuando existen reglas, las desviaciones respecto de ellas no son simples fundamentos para la predicción de que sobrevendrán reacciones hostiles o de que un tribunal aplicará sanciones a quienes las transgreden; tales desviaciones son también una razón o justificación para dichas reacciones y sanciones" ${ }^{\text {41 }}$.

En definitiva, los enunciados internos no pueden ser reducidos a enunciados externos, pero tampoco los enunciados externos pueden ser reducidos a enunciados internos, en cuanto estos últimos no describen la "eficacia" o la "efectividad" de las normas (esto es, no dicen, ni implican, que se trata de normas vigentes). Volviendo al libro de Shapiro, uno podría tener la impresión de que el autor está más interesado en los enunciados internos que en los externos. Claramente Shapiro comparte la distinción, pero la teoría del derecho como plan parece encajar mejor con los enunciados internos y descuidar los externos, puesto que está casi exclusivamente construida sobre la perspectiva de los planificadores, es decir, la perspectiva de quienes crean nuestras instituciones jurídicas, adoptan el derecho y se preocupan por él ${ }^{42}$.

\section{IV.2. La defensa de Ross}

Unos pocos años luego de la reseña de Hart, Ross publicó una reseña del libro de Hart, El concepto de derecho. Ross parece ser menos crítico con Hart, de lo que Hart lo fue con él. Ross no quiere descuidar la distinción interno/externo de los enunciados jurídicos. Por el contrario,

${ }^{41}$ Hart, H. L. A., The Concept of Law, op. cit., p. 84 (105).

${ }^{42}$ Véase Shapiro, S. J., "The Bad Man and the Internal Point of View", op. cit.; Id., "What is the Internal Point of View?", op. cit.; y Shapiro, S., Legalidad, op. cit., pp. 138-139. Digo "casi exclusivamente" puesto que a veces Shapiro realiza afirmaciones externas tales como "La creación de derecho no intencional es posible" (Shapiro, S., Legalidad, op. cit., p. 106) o las "normas similares a los planes deben ser analizadas de un modo diferente a los planes, dado que pueden surgir de modo no intencional" (Shapiro, S., Legalidad, op. cit., p. 464). 
las ambiciones científicas de una teoría realista dependen precisamente de esa distinción.

De mi parte, quiero agregar que el lenguaje interno no es un lenguaje de naturaleza descriptiva. La función del lenguaje interno no es la de describir hechos, ni la de proporcionar información; su función es, en cambio, la de advertir, reprender, exhortar. Cuando digo "Te he prestado mi auto. Tienes el deber de cuidarlo", mi intención es exigir una determinada conducta de parte de quien recibió mi auto y justificar esta exigencia haciendo referencia a las normas (jurídicas o morales) acerca del préstamo. No informo a quien recibió el auto sobre la existencia de tales reglas, las aplico. El lenguaje externo, por otro lado, es de naturaleza descriptiva. Se refiere a hechos, a la descripción y a la predicción de hechos ${ }^{43}$.

Los jueces, y otros funcionarios que aplican el derecho, usan un "lenguaje interno" normativamente cargado. Lo mismo es verdad, podríamos agregar, de los ciudadanos que aceptan y obedecen el derecho. Ellos muestran lo que Hart llama "actitud crítico-reflexiva" 44. Pero la ciencia jurídica no usa el mismo lenguaje, usa un "lenguaje externo" que hace abstracción de esa aceptación.

Me sorprende verdaderamente que Hart no advierta, o que al menos no mencione, el más obvio de los usos de un lenguaje externo por parte de un observador, que ni acepta ni rechaza las normas, sino que meramente informa acerca de ellas: el estudioso del derecho cuyo trabajo es proporcionar enunciados verdaderos acerca del derecho existente ${ }^{45}$.

El estudioso del derecho, cuya tarea es describir el derecho como un observador interesado en obtener conocimiento jurídico, debe evitar

${ }^{43}$ Ross, A., "Reseña de 'The Concept of Law' de H. L. A. Hart”, The Yale Law Journal, 71, 1962, pp. 1185-1190, cita en la p. 1189.

${ }^{44}$ Hart, H. L. A., The Concept of Law, op. cit., p. 56 y ss. (70 y ss). Véase Ross, A., On Law and Justice, op. cit., pp. 34 y ss.

45 Ross, A., "Reseña de 'The Concept of Law'”, op. cit., p. 1189. 
¿En qué se equivoca el realismo jurídico?

el lenguaje interno de los participantes. "Yo me ocupo del enunciado externo acerca de las existencia de una norma o de un sistema de normas." ${ }^{46}$. Por lo tanto, según el filósofo dinamarqués, no parece existir ningún desacuerdo entre él y Hart, puesto que ambos consideran que la existencia de normas jurídicas es una cuestión empírica que depende de la práctica judicial:

Hart comparte la opinión de que la existencia de una norma o de un sistema de normas es una cuestión empírica, acerca de hechos que dependen del modo en que los tribunales efectivamente identifican lo que cuenta como derecho ${ }^{47}$.

Ross sostiene que la fuente del malentendido entre ambos es el término "validez". Ross afirma que el término "válido", usado en la traducción inglesa de su libro, no era una buena opción, puesto que el término original dinamarqués significaba algo como "vigente" o "eficaz"48. Las teorías predictivas son teorías del conocimiento jurídico, i. e., del conocimiento del derecho "vigente". En este sentido no existe incompatibilidad entre estas teorías y el concepto positivista de derecho hartiano.

Omitiendo aquí algunas complicaciones, una forma extremamente cruda de realismo produciría enunciados del siguiente tipo (" $\mathrm{x}$ " es una variable para individuos, "C" significa "realiza la acción C", "S" significa "es sancionado por un tribunal", " $\forall$ " es el cuantificador universal y “ $\rightarrow$ ” es el símbolo de la implicación material):

46 Ibidem, p. 1190. Véase Kelsen, H., op. cit., p. 164: "La teoría del derecho normativa describe el derecho desde un punto de vista externo, aun cuando sus enunciados son enunciados de deber ser". Algunos filósofos sostienen que el Realismo jurídico escandinavo constituyó el intento más interesante y coherente de naturalizar (y de, en cierto sentido, "externalizar") la ciencia del derecho; véase Spaak, T., op. cit.

${ }^{47}$ Ross, A., "Reseña de 'The Concept of Law”, op. cit., p. 1190. En realidad esto no es exactamente así. Hart afirma esto con relación al sistema en su totalidad, y no respecto de cada norma individual.

48 Ibidem, p. 1190. 
(A) $\quad \forall x(\mathrm{C} x \rightarrow \mathrm{S} x)$.

El problema con los enunciados del tipo (A) es que pasan por alto la dimensión normativa del derecho, del comportamiento jurídico y del proceso de toma de decisiones ${ }^{49}$. Los enunciados externos de Ross, por el contrario, tienen, en mi opinión, la siguiente forma lógica ("O" es operador deóntico de obligación):

$$
\mathrm{O}(\forall x(\mathrm{C} x \rightarrow \mathrm{S} x))
$$

Lo que este tipo de enunciado dice es: es el caso que es obligatorio (según las actitudes normativas de los tribunales) que tal y cual conducta sea sancionada por los tribunales. Enunciados del tipo (B) no pasan por alto la normatividad del derecho. Aun así, siendo descriptivos, estos enunciados son diferentes de los enunciados internos de los participantes, los que puede ser expresados como poseyendo la forma siguiente:

$$
\text { ¡O }(\forall x(\mathrm{C} x \rightarrow \mathrm{S} x)) !
$$

La marca distintiva de esta última clase de enunciados es su fuerza normativa; ellos no informan acerca de las actitudes de los tribunales, sino que expresan, ellos mismo, una actitud normativa. La perspectiva científica y realista de Ross pretende proporcionar enunciados del tipo (B), ya que los enunciados del tipo (A) son claramente inadecuados y enunciados del tipo (C) son enunciados de los participantes, formulados desde el punto de vista interno. $\mathrm{O}$, mejor, un cuadro realista combina enunciados del tipo (A) y (B), es decir, enunciados predictivos acerca del comportamiento judicial y enunciados acerca de las actitu-

49 "Una orden o un comando no es sólo toda señal a la que se responde apropiadamente de un modo y no de otro. Es algo que determina qué es una respuesta apropiada a través del decir lo que uno tiene que hacer, describiéndolo, especificando qué conceptos han de aplicarse a una acción para que ésta cuente como obedecer la orden" (Brandom, R. B., Reason in Philosophy. Animating Ideas, Cambridge and London, Harvard University Press, 2009, p. 175). 
¿En qué se equivoca el realismo jurídico?

des judiciales, en cuanto el comportamiento judicial es evidencia de las actitudes judiciales ${ }^{50}$. Todo ello para no mencionar el hecho de que, conocer el derecho también consiste en el conocimiento de un conjunto complejo de hechos sociales ${ }^{51}$. Esto presupone, por supuesto, una cierta teoría acerca de lo que el derecho es. Por ejemplo, podría presuponer una teoría positivista del derecho. Creo que esta actitud realista es también compatible con la teoría del derecho como plan de Shapiro. Pero, para poder afirmar esto último, es necesario determinar si una pura descripción del derecho vigente es posible dentro del esquema de Shapiro, en el que se asume el punto de vista de los planificadores, esto es, un punto de vista según el cual el derecho posee un fin moral y está diseñado para resolver problemas morales ${ }^{52}$. Puesto que una cosa es el hecho que los planes sean obligatorios para los tribunales, otra cosa es que sean eficaces.

${ }^{50}$ Véase Ross, A., On Law and Justice, op. cit., pp. 70-74. Pero entonces, ¿qué sucede con la normatividad del derecho, es decir, con "la idea según la cual las normas jurídicas válidas proporcionan específicas razones para la acción en virtud de su juridicidad" (Leiter, B., op. cit., p. 188)? "En tanto y en cuanto las razones jurídicas delimiten el rango de resultados permitidos, la normatividad del derecho figurará en la mejor explicación de la decisión, incluso si el resultado final (elegido entre aquellos que pueden ser legalmente racionalizados) es un producto de una actitud ideológica y no tanto de un razonamiento jurídico" (ibidem, p. 190). Esto involucra una versión deflacionada de la noción en cuestión. "Seguramente, admitir la posibilidad de 'hablar de la normatividad del derecho', dentro de nuestra teoría socio-científica de la decisión judicial, exige una deflación de las afirmaciones acerca de la obligación jurídica, que va todavía más allá de la que llevara a cabo Hart en su teoría original. Pasamos de 'los jueces se ven a ellos mismos como teniendo obligaciones' a 'los jueces hablan como si se vieran a ellos mismos como teniendo obligaciones"' (ibidem, p. 191).

${ }^{51}$ Véase, e. g., Hierro, L., "Realismo jurídico", en Garzón, E. y Laporta, F. J. (eds.), Enciclopedia iberoamericana de filosofia, vol. 11, Madrid, Editorial Trotta-Consejo Superior de Investigaciones Científicas, 1996, pp. 77-86 y Id., El realismo jurídico escandinavo. Una teoría empirista del derecho, 2. ${ }^{a}$ ed., Madrid, Iustel, 2009.

52 Por supuesto que Shapiro sostiene que esto es posible (Shapiro, S., Legalidad, op. cit., pp. 239-240): "los enunciados jurídicos son descriptivos [...] porque describen la perspectiva moral del derecho". Pero esto parece ser una descripción de las actitudes de los planificadores, y tales actitudes pueden ser diferentes del derecho "efectivamente vigente". 


\section{V. ¿Cuántos realismos?}

Leiter dice que el realismo jurídico estadounidense poseía una teoría de la decisión judicial y no una teoría del derecho estrictamente hablando ${ }^{53}$. Lo que Leiter busca al afirmar esto es contestar algunas de las objeciones de Hart y conciliar el realismo jurídico con el positivismo jurídico. Leiter sostiene que el primero, pero no el último, posee una teoría descriptiva (correcta) de la decisión judicial, mientras que el segundo, pero no el primero, provee un análisis conceptual (correcto) de lo que el derecho es. Leiter piensa que la concepción realista del derecho es simplemente la de los positivistas (de acuerdo con la cual la validez jurídica es una cuestión de pedigree $)^{54}$.

Pienso que el realismo jurídico, como cualquier otra teoría del derecho, posee una teoría y una ontología del derecho, más o menos implícitas $^{55}$. Así, a pesar de lamentarse de la metafísica, el realismo también poseía una teoría de la naturaleza del derecho. No estoy seguro de que se trate simplemente de una teoría positivista. La distinción de Gray entre derecho y fuentes del derecho, o la de Pound entre derecho en acción y derecho en los libros - para mencionar solo algunas de las piedras angulares del realismo- son poco positivistas, aun cuando sea posible encontrarles un lugar dentro del esquema positivista ${ }^{56}$. De acuerdo a la ontología jurídica de los realistas, el derecho está (principalmente) hecho por las decisiones de los jueces, y las predicciones de esas deci-

${ }^{53}$ Leiter, B., op. cit., cap. 2. Sin embargo, Green, L., op. cit., p. 4, señala que quizás aun no tengamos una buena teoría predictiva de la decisión judicial.

54 "Así, a nivel filosófico o conceptual, el realismo y el positivismo son bien compatibles $\mathrm{y}$, de hecho, el primero necesita al segundo. A nivel empírico, resulta que, mientras que existe un genuino desacuerdo entre las dos teorías, ni Hart ni ningún otro filósofo del derecho ha ofrecido un verdadero argumento contra el punto de vista realista" (Leiter, B., op. cit., p. 60).

55 Véase Tuzet, G., "The Social Reality of Law”, en Comanducci, P. y Guastini, R. (eds.), Analisi e diritto 2007, Torino, Giappichelli, 2007, pp. 179-198.

56 Véase Gray, J. C., The Nature and Sources of the Law, New York, The Columbia University Press, 1909 y Pound, R., "Law in Books and Law in Action", American Law Review, 44, 1910, pp. 12-36. Estas teorías pueden ser convenientemente ubicadas dentro de un marco positivista definido por la tesis de las fuentes. 
¿En qué se equivoca el realismo jurídico?

siones constituyen un modo de obtener conocimiento acerca de este. Si la teoría predictiva fuera una teoría sobre la naturaleza del derecho, se trataría, en virtud de las razones mencionadas más arriba, de una teoría claramente defectuosa ${ }^{57}$. Esto no implica que sea una teoría equivocada acerca del conocimiento jurídico o una teoría descriptiva equivocada de la decisión judicial.

Leiter sostiene que los realistas eran "escépticos ante las reglas en sentido empírico", en el sentido de que sostenían que, en las decisiones judiciales, las normas jurídicas no desempeñan el papel que se les atribuye. El escepticismo empírico ante las reglas es distinto del escepticismo conceptual ante las reglas. Este último es una versión mucho más fuerte de escepticismo según el cual las reglas son lo que los tribunales dicen que son y, en consecuencia, "hace que sea imposible articular la idea, bastante simple, de que el derecho es una cosa, y la decisión de un determinado tribunal otra" ${ }^{58}$. El escepticismo conceptual viola la verdad obvia referida a la objetividad, usando el vocabulario de Shapiro. El defensor del escepticismo empírico ante las reglas sostiene, en cambio, que las reglas jurídicas no son eficaces, que no tienen eficacia causal respecto de las decisiones judiciales (al menos en algunos contextos de apelación) ${ }^{59}$. Las decisiones de los tribunales no están determinadas - $\mathrm{O}$ al menos se encuentran subdeterminadas- por las reglas. Ahora bien, substitúyase "reglas" por "planes" y la misma preocupación aparece respecto de la teoría de Shapiro. ¿Poseen los planes eficacia causal respecto de las decisiones judiciales?

Asumamos, siguiendo a Shapiro, que la actividad jurídica es una forma de planificación social ("la tesis de la planificación"), que las reglas jurídicas son planes y que son obligatorias para los tribunales ${ }^{60}$.

${ }^{57}$ Ignora el punto de vista interno y no puede dar cuenta de las reglas secundarias hartianas.

${ }^{58}$ Leiter, B., op. cit., p. 70.

${ }^{59}$ Ibidem, pp. 73-79. Así, Leiter afirma que "Hart tiene buenos argumentos contra el escepticismo conceptual ante las reglas, pero esta forma de escepticismo no es, de hecho, la de los realistas jurídicos; y, en segundo lugar, que Hart nunca ofrece argumentos contra el escepticismo empírico ante las reglas" (ibidem, p. 69).

60 Véase Shapiro, S., Legalidad, op. cit., caps. 6-7. 
Un conjunto diferente de cuestiones involucraría las siguientes preguntas: ¿cuándo un plan es eficaz?, ¿cómo puede determinarse empíricamente su eficacia?, ¿son los planes eficaces por definición?, ¿la noción de "plan que fracasa" es una noción contradictoria? ${ }^{61}$. No estoy seguro de que haya, dentro de la teoría de los planes espacio conceptual para una descripción de planes que fracasan ${ }^{62}$. Para que haya espacio es necesario que la teoría diga (cómo determinar) si un plan es eficaz o no en un contexto dado y, en particular, si los realistas estaban en lo cierto o no acerca de la indeterminación del derecho. Así, para decirlo en términos de Leiter, ¿ofrece la teoría de los planes una adecuada teoría descriptiva de la decisión judicial? Y, si lo hace, ¿provee una adecuada teoría descriptiva del derecho vigente?

Si nos concentramos en la decisión judicial, nos daremos cuenta de que los realistas no se contentaban con una simple teoría descriptiva, sostenían además que algunos métodos para decidir casos eran, de hecho, buenos métodos. En tanto y en cuanto ponderaban ciertos métodos y criterios de decisión, los realistas poseían una teoría prescriptiva de la decisión judicial. Los detalles de esta teoría eran distintos en cada autor y en cada contexto legal (resolver una controversia comercial no es lo mismo que decidir un caso penal, seguramente), pero los realistas compartían un interés por específicos conceptos, métodos y criterios y despreciaban las generalidades y las abstracciones. Cuando los casos eran decididos considerando las consecuencias sociales de la decisión, o las consecuencias económicas de la controversia, o los hechos particulares en cuestión, en lugar de considerar los conceptos o doctrinas legales, los realistas consideraban a esos casos decididos correctamente. Según los realistas, para citar un buen ejemplo, MacPherson fue

${ }^{61}$ Según Shapiro, los planes "no solo son entidades positivas que tienen una estructura anidada, sino que se forman en un proceso que dispone a sus sujetos a obrar en conformidad. En consecuencia, salvo que exista una disposición a observarlas, las normas creadas para guiar la conducta de los miembros de la comunidad no serán planes" (Shapiro, S., Legalidad, op. cit., p. 227).

62 Shapiro es consciente del problema, puesto que los planes pueden fracasar y no alcanzar sus metas, en particular, sus metas morales. "El derecho es derecho porque tiene un fin moral, no porque lo satisface" (Shapiro, S., Legalidad, op. cit., p. 266). 
¿En qué se equivoca el realismo jurídico?

un caso bien decidido por Cardozo en $1916^{63}$. En definitiva, los realistas poseían una teoría prescriptiva y evaluativa de la decisión judicial, no solo una descriptiva. Uno podría preguntarse si un enfoque de este tipo es preferible respecto de la teoría de los planes cuando se trata de aplicarlo a la interpretación jurídica y a la toma de decisión en el derecho ${ }^{64}$, especialmente cuando los planes que deberíamos emplear para resolver ciertos problemas fueron diseñados en condiciones morales y sociales diferentes.

Si todo esto es cierto, para resumir lo que ha sido dicho hasta aquí, el realismo jurídico puede ser concebido y defendido en al menos cuatro modos:

1) como una teoría acerca de la naturaleza del derecho;

2) como una teoría acerca del conocimiento jurídico;

3) como una teoría descriptiva de la decisión judicial;

4) como una teoría prescriptiva de la decisión judicial.

En el primer sentido ha sido demostrado que es una teoría falsa. En el segundo y tercer sentidos existen buenas razones para considerarla una teoría verdadera (recuérdese lo que hemos dicho acerca de Holmes y Ross). En el cuarto sentido existen buenas razones para considerarla una buena teoría (considérese el caso MacPherson y otros similares). Este, de todos modos, no es el lugar en el que podemos resolver estas cuestiones. Pero como conclusión ellas sugieren algunas dudas acerca de la teoría de Shapiro. La primera es la siguiente: ¿cuáles son exactamente los enunciados externos disponibles para el estudioso del derecho que acepta la teoría de los planes? ¿Existe un espacio conceptual, dentro de esta teoría, para aquellos enunciados que simplemente describen el derecho vigente en un cierto contexto, haciendo abstracción de su corrección moral y a pesar de la tesis del "fin moral"?

${ }^{63}$ Véase Leiter, B., "In Praise of Realism (and Against 'Nonsense' Jurisprudence)", The Georgetown Law Journal, 100, 2012, pp. 865-893. Véase Posner, R. A., "Pragmatic Adjudication", Cardozo Law Review, 18, 1996, pp. 1-20 y Shapiro, S., Legalidad, op. cit., p. 416 y ss.) sobre la "decisión judicial pragmatista" de Posner.

${ }^{64}$ Véase Shapiro, S., Legalidad, op. cit., cap. 13. 
En otras palabras, no tengo del todo claro dónde queda, en la teoría de Shapiro, la línea divisoria entre los enunciados internos y los enunciados externos. Incluso más, “QQué es derecho?” y “¿Qué establece el derecho?" son preguntas diferentes, y los realistas estaban más interesados en la última que en la primera ${ }^{65}$. Uno podría tener la impresión de que la teoría de los planes se encuentra más interesada en la primera y carece de una clara explicación para la última y del modo en el que el conocimiento jurídico puede ser obtenido. En este sentido, sería de ayuda saber con precisión si es posible que existan planes que fracasan y cómo es posible detectarlos empíricamente. En mi experiencia, una de las características más comunes de la vida social es que las cosas no salen como deberían. En este sentido, sería extraño sostener que los planes son exitosos por definición.

La segunda preocupación, bastante diferente de la primera ${ }^{66}$, es la siguiente: ¿es Shapiro más realista que Leiter? Una conclusión de este tipo podría ciertamente sorprender, pero no tanto si se tiene en cuenta que la base sobre la que Shapiro sostiene que las normas jurídicas son planes es la siguiente: somos criaturas que planifican y las condiciones de nuestra vida social (en particular, las denominadas "circunstancias de la legalidad" ${ }^{7}$ ), junto con las normas de racionalidad, nos conducen a esa forma de planificación social que consiste en el establecimiento de un sistema jurídico.

La existencia del derecho [...] refleja el hecho de que los seres humanos somos seres que planifican, dotados de capacidades cognitivas y volitivas para organizar el comportamiento a lo

${ }^{65}$ Véase Ross, A., On Law and Justice, op. cit., p. 31.

${ }^{66}$ En su contribución a este volumen Papayannis señala, en mi opinión correctamente, que el libro de Shapiro admite una doble lectura, a saber, una lectura interna y una externa, una que ofrece una explicación del derecho en términos de propósitos y otra que ofrece una explicación del derecho en términos de funciones.

67 "Las circunstancias de la legalidad se producen cuando una comunidad afronta muchos y serios problemas morales cuyas soluciones son complejas, controvertidas o arbitrarias. En tales casos, los beneficios de planificar serán elevados, pero también lo serán los costes y los riesgos asociados con otras formas de ordenar el comportamiento, tales como la improvisación, el orden espontáneo, los acuerdos privados, el consenso de la comunidad o las jerarquías personalizadas" (Shapiro, S., Legalidad, op. cit., p. 217). 
¿En qué se equivoca el realismo jurídico?

largo del tiempo y entre las personas a fin de alcanzar metas muy complejas ${ }^{68}$.

Si no me equivoco, el trasfondo de la teoría de los planes es de tipo funcionalista, incluso su vocabulario es al menos en parte el vocabulario de las funciones ${ }^{69}$. En cierto sentido, esta teoría es una explicación naturalista de por qué tenemos cosas tales como normas jurídicas e instituciones. Podría pensarse que el "fin moral" del derecho también puede explicarse sobre esta base. Se trata de algo que necesitamos en virtud de nuestra racionalidad instrumental, de las condiciones de la vida social y de las "circunstancias de la legalidad" mente naturalizada, podría pensarse, jes la de Shapiro, y no la de Leiter! Es cierto que Shapiro comienza su libro con un elogio del análisis conceptual, pero podría tratarse nada más que de un comienzo conmemorativo, sin efectos reales sobre el resto de los argumentos y conclusiones del libro. Debo confesar que esta lectura de Shapiro es realmente arriesgada, pero me pregunto si no se trataría de un modo empíricamente más robusto de construir y defender la teoría del derecho como plan.

\section{Bibliografía}

Brandom, R. B., Reason in Philosophy. Animating Ideas, Cambridge and London, Harvard University Press, 2009.

Burton, S. J. (ed.), The Path of the Law and its Influence, Cambridge, Cambridge University Press, 2000.

${ }^{68}$ Shapiro, S., Legalidad, op. cit., p. 202.

${ }^{69}$ Véase e. g. Shapiro, S., Legalidad, op. cit., p. 216 y ss. Sin embargo, Shapiro sugiere en varios puntos de su libro que sus tesis son conceptuales y basadas en experimentos mentales (Shapiro, S., Legalidad, op. cit., p. 201). Asimismo, algunas referencias explícitas a las funciones del derecho han sido borradas de la penúltima versión del texto (un hecho que testimonia las intenciones del autor pero que no modifica la naturaleza de sus argumentos). La última versión contiene aproximadamente 80 apariciones del término "función" o sus derivados, mientras que la penúltima versión contenía casi 100.

${ }^{70}$ Shapiro, S., Legalidad, op. cit., p. 265: "el objeto fundamental de la actividad jurídica es solucionar las deficiencias morales de las circunstancias de la legalidad". 
Chiassoni, P., "Richard Posner: pragmatismo e analisi economica del diritto", en Zanetti, G. (ed.), Filosofi del diritto contemporanei, Milano, Raffaello Cortina, 1999, pp. 183-220.

Fisch, M. H., "Justice Holmes, the Prediction Theory of Law, and Pragmatism", The Journal of Philosophy, 39, 1942, pp. 85-97.

Gray, J. C., The Nature and Sources of the Law, New York, The Columbia University Press, 1909.

Green, L., "Law and the Causes of Judicial Decisions", University of Oxford Legal Research Paper Series, 14/2009, pp. 1-36.

Grey, T. C., "Holmes and Legal Pragmatism", Stanford Law Review, 41, 1989, pp. 787-870.

Haack, S., "On Legal Pragmatism: Where Does 'The Path of the Law' Lead Us?", The American Journal of Jurisprudence, 50, 2005, pp. 71-105. Hart, H. L. A. (1959), "Scandinavian Realism", en Id., Essays in Jurisprudence and Philosophy, Oxford, Clarendon Press, 1983, pp. 161-169.

Hart, H. L. A. (1961), The Concept of Law, Second Edition, Oxford, Oxford University Press, 1994.

Hart, H. L. A., El concepto de derecho, Buenos Aires, Abeledo-Perrot, 1963, traducción de Genaro Carrió.

Hierro, L., "Realismo jurídico", en Garzón, E. y Laporta, F. J. (eds.), Enciclopedia iberoamericana de filosofia, vol. 11, Madrid, Editorial TrottaConsejo Superior de Investigaciones Científicas, 1996, pp. 77-86.

Hierro, L., El realismo jurídico escandinavo. Una teoría empirista del derecho, 2. ${ }^{a}$ ed., Madrid, Iustel, 2009.

Holmes, O. W., "The Path of the Law", Harvard Law Review, 10, 1897, pp. 457-478.

Kelsen, H. (1945), General Theory of Law and State, New York, Russell \& Russell, 1961.

Leiter, B., Naturalizing Jurisprudence. Essays on American Legal Realism and Naturalism in Legal Philosophy, Oxford, Oxford University Press, 2007. Leiter, B., "In Praise of Realism (and Against 'Nonsense' Jurisprudence)", The Georgetown Law Journal, 100, 2012, pp. 865-893.

Miles, T. J., y Sunstein, C. R., "The New Legal Realism", University of Chicago Law Review, 75, 2008, pp. 831-851. 
¿En qué se equivoca el realismo jurídico?

Miller, J. D., "Holmes, Peirce and Legal Pragmatism", The Yale Law Journal, 84, 1975, pp. 1123-1140.

Minda, G., Postmodern Legal Movements. Law and Jurisprudence at Century's End, New York, New York University Press, 1995.

Muffato, N., "Asserti interni: prescrizioni o asserzioni?", en Comanducci, P. y Guastini, R. (eds.), Analisi e diritto 2007, Torino, Giappichelli, 2007, pp. 11-37.

Nourse, V. y Shaffer, G., "Varieties of New Legal Realism: Can a New World Order Prompt a New Legal Theory?", Cornell Law Review, 95, 2009, pp. 61-137.

Perry, S. R., "Holmes versus Hart: The Bad Man in Legal Theory", en Burton, S. J. (ed.), The Path of the Law and its Influence, Cambridge, Cambridge University Press, 2000, pp. 158-196.

Posner, R. A., The Economics of Justice, Cambridge and London, Harvard University Press, 1981.

Posner, R. A., The Problems of Jurisprudence, Cambridge and London, Harvard University Press, 1990.

Posner, R. A., "Pragmatic Adjudication", Cardozo Law Review, 18, 1996, pp. 1-20.

Posner, R. A., How Judges Think, Cambridge and London, Harvard University Press, 2008.

Pound, R., "Law in Books and Law in Action", American Law Review, 44, 1910, pp. 12-36.

Priel, D., "Were the Legal Realists Legal Positivists?", Law and Philosophy, 27, 2008, pp. 309-350.

Ross, A., On Law and Justice, London, Stevens \& Sons, 1958.

Ross, A., "Reseña de 'The Concept of Law' de H.L.A. Hart", The Yale Law Journal, 71, 1962, pp. 1185-1190.

Schauer, F., "Was Austin Right After All? On the Role of Sanctions in a Theory of Law", Ratio Juris, 23, 2010, pp. 1-21.

Shapiro, S., "On Hart's Way Out", Legal Theory, 4, 1998, pp. 469-507. Shapiro, S., "The Bad Man and the Internal Point of View", en Burton, S. J. (ed.), The Path of the Law and its Influence, Cambridge, Cambridge University Press, 2000, pp. 197-210. 
Shapiro, S., "Law, Morality, and the Guidance of Conduct", Legal Theory, 6, 2000, pp. 127-170.

Shapiro, S., "Law, Plans, and Practical Reason", Legal Theory, 8, 2002, pp. 387-441.

Shapiro, S., "What is the Internal Point of View?", Fordham Law Review, 75, 2006, pp. 1157-1170.

Shapiro, S., Legalidad, Madrid-Barcelona, Marcial Pons, 2014, traducción de Papayannis, D. M. y Ramírez Ludeña, L.

Spaak, T., Reseña de "Naturalizing Jurisprudence" de B. Leiter, Theoria, 74, 2008, pp. 352-362.

Tuzet, G., "The Social Reality of Law", en Comanducci, P. y Guastini, R. (eds.), Analisi e diritto 2007, Torino, Giappichelli, pp. 179-198.

Twining, W., "The Bad Man Revisited", Cornell Law Review, 58, 1973, pp. 275-303.

Von Wright, G. H., Norm and Action, London, Routledge \& Kegan Paul, 1963.

White, M., "Holmes and Hart on Prediction and Legal Obligation", Transactions of the Charles S. Peirce Society, 2004, 40, pp. 569-573. 